\title{
Contemporary treatment of renal trauma in Canada
}

\author{
Ron Kodama, MD, FRCSC \\ Division of Urology, Department of Surgery, University of Toronto, Toronto, ON, Canada
}

Cite as: Can Urol Assoc J 2019;13(6Suppl4):S46-50. http://dx.doi.org/10.5489/cuai.5980

\section{Introduction}

This section will summarize the current management of high-grade renal injuries. It is not meant to be an all-encompassing review of the topic but will highlight important diagnostic and treatment principles.

Renal trauma occurs in approximately $1 \%$ of all patients admitted to a trauma unit. ${ }^{1,2}$ Approximately $80 \%$ of those renal injuries are secondary to blunt injury. ${ }^{3}$ The kidneys are the most common genitourinary organ (approximately $40 \%$ ) to be injured in patients involved in traffic accidents. Interestingly, in one series, the testes are the second most injured organs after the kidneys in motorcycle or bicycle accidents. Ureteric injuries in blunt injuries are uncommon $(<1 \%) .{ }^{4}$ Recently, Mann et al published their contemporary experience of managing renal trauma in a Canadian level 1 trauma unit. $^{5}$

\section{Classification of renal trauma}

Renal injuries are classified according to the American Association for the Surgery of Trauma (AAST). For many years, the 1989 classification was used. ${ }^{6}$ In this grading system, high-grade renal injuries (Grade 3 and above) were defined by the depth of laceration, involvement of the collecting system, and whether the main renal artery/vein were involved. Grade 4 injuries included injuries to the collecting system and main renal artery and vein with contained hemorrhage. Grade 5 injuries included a "shattered kidney" or renal hilum avulsion. Unfortunately, renal injuries do not always follow the grading system. Devascularization of the renal parenchyma, segmental arterial hemorrhage, and multiple lacerations into the collecting system often occur in these high-grade injuries. The definition of a shattered kidney was ambiguous in the AAST 1989 grading system.

Buckley et $\mathrm{al}^{7}$ proposed a revision of this grading scale to better define Grade 4 and 5 injuries and help overcome these deficiencies. In this grading scale, all segmental vascular injuries and collecting system injuries (including uretero- pelvic junction [UPJ] avulsion and renal pelvis lacerations), regardless of the number, were classified as Grade 4 injuries. Grade 5 injuries were exclusively defined as only main hilar vessel injuries. In their series of patients, the renal salvage rate and nephrectomy rate were identical when the injuries were reclassified from the 1989 system to their revised proposal. Moreover, Dugi et al, ${ }^{8}$ further expanded and classified highrisk Grade 3-4 injuries requiring intervention by the size of the perirenal hematoma $(>3.5 \mathrm{~cm})$, the site of the laceration (medial worse than lateral), and the presence of intravascular contrast extravasation (VCE) seen on the portal-venous phase of the computed tomography (CT) scan. Kidneys having two or all three of these high-risk factors required a higher rate of intervention (66\% compared to $7 \%$ if only one was present). Similarly, in another retrospective study, patients with Grade 4 injuries with two or more of these high-risk features were $25 \%$ more likely to require intervention. ${ }^{9}$

Recently, there has been an update to the AAST classification (Table 1). ${ }^{10}$ The new AAST classification appears to take into account the proposed changes of Buckley et al. A Grade 5 injury still has a "shattered kidney" in the classification, which has been defined as the "loss of identifiable parenchymal renal anatomy." The author still has concerns on the exact definition of a Grade 5 injury, however, taken literally, this would be interpreted as the severest form of renal parenchymal injury.

\section{Indications for imaging}

The indications for CT scanning in suspected renal injuries are well-known. These include patients with blunt abdominal injury with gross hematuria; patients with microscopic hematuria associated with the presence of shock $(<90 \mathrm{mmHg})$; and patients with penetrating trauma to the abdomen, flank, or upper chest. Other indications include a history (rapid deceleration or previous known urological renal abnormality) or physical exam (flank or upper abdominal skin bruising, lower rib or thoracic/upper lumbar vertebral fracture) that may direct the clinician to suspect a renal injury. It must be remembered that hematuria (microscopic or gross) may not be present, even in patients with major renal injuries. In the majority of these cases, CT abdominal scanning is done for 


\begin{tabular}{|c|c|c|c|c|}
\hline $\begin{array}{l}\text { AAST } \\
\text { grade }\end{array}$ & $\begin{array}{c}\text { AIS } \\
\text { severity }\end{array}$ & Imaging criteria (CT findings) & Operative goals & Pathological criteria \\
\hline I & 2 & $\begin{array}{l}\text { - Subcapsular hematoma and/or } \\
\text { parenchymal contusion without } \\
\text { laceration }\end{array}$ & $\begin{array}{l}\text { - Non-expanding subcapsular } \\
\text { hematoma } \\
\text { - Parenchymal contusion without } \\
\text { laceration }\end{array}$ & $\begin{array}{l}\text { - Subcapsular hematoma or } \\
\text { parenchymal contusion without } \\
\text { parenchymal laceration }\end{array}$ \\
\hline II & 2 & $\begin{array}{l}\text { - Peri-renal hematoma confined to } \\
\text { Gerota fascia } \\
\text { - Renal parenchymal laceration } \leq 1 \mathrm{~cm} \\
\text { depth without urinary extravasation }\end{array}$ & $\begin{array}{l}\text { - Non- expanding peri-renal } \\
\text { hematoma confined to Gerota fascia } \\
\text { - Renal parenchymal laceration } \leq 1 \mathrm{~cm} \\
\text { depth without urinary extravasation }\end{array}$ & $\begin{array}{l}\text { - Peri-renal hematoma confined to } \\
\text { Gerota fascia } \\
\text { - Renal parenchymal laceration } \leq 1 \mathrm{~cm} \\
\text { depth without urinary extravasation }\end{array}$ \\
\hline III & 3 & $\begin{array}{l}\text { - Renal parenchymal laceration } \\
>1 \mathrm{~cm} \text { depth without collecting } \\
\text { system rupture or without urinary } \\
\text { extravasation } \\
\text { - Any injury in the presence of a } \\
\text { kidney vascular injury or active } \\
\text { bleeding contained within Gerota } \\
\text { fascia }\end{array}$ & $\begin{array}{l}\text { - Renal parenchymal laceration } \\
>1 \mathrm{~cm} \text { depth without collecting } \\
\text { system rupture or without urinary } \\
\text { extravasation }\end{array}$ & $\begin{array}{l}\text { - Renal parenchymal laceration } \\
>1 \mathrm{~cm} \text { depth without collecting } \\
\text { system rupture or without urinary } \\
\text { extravasation }\end{array}$ \\
\hline IV & 4 & $\begin{array}{l}\text { - Parenchymal laceration extending } \\
\text { into urinary collecting system with } \\
\text { urinary extravasation } \\
\text { - Renal pelvis laceration and/or } \\
\text { complete ureteropelvic disruption } \\
\text { - Segmental renal vein or artery injury } \\
\text { - Active bleeding beyond Gerota } \\
\text { fascia into the retroperitoneum or } \\
\text { peritoneum } \\
\text { - Segment or complete kidney } \\
\text { infarction(s) due to vessel thrombosis } \\
\text { without active bleeding }\end{array}$ & $\begin{array}{l}\text { - Parenchymal laceration extending } \\
\text { into urinary collecting system with } \\
\text { urinary extravasation } \\
\text { - Renal pelvis laceration and/or } \\
\text { complete ureteropelvic disruption } \\
\text { - Segmental renal vein or artery injury } \\
\text { - Segment or complete kidney } \\
\text { infarction(s) due to vessel } \\
\text { thrombosis without active bleeding }\end{array}$ & $\begin{array}{l}\text { - Parenchymal laceration extending } \\
\text { into urinary collecting system } \\
\text { - Renal pelvis laceration and/or } \\
\text { complete ureteropelvic disruption } \\
\text { - Segmental renal vein or artery injury } \\
\text { - Segment or complete kidney } \\
\text { infarction(s) due to vessel } \\
\text { thrombosis without active bleeding }\end{array}$ \\
\hline V & 5 & $\begin{array}{l}\text { - Main renal artery or vein laceration } \\
\text { or avulsion of hilum } \\
\text { - Devascularized kidney with active } \\
\text { bleeding } \\
\text { - Shattered kidney with loss of } \\
\text { identifiable parenchymal renal } \\
\text { anatomy }\end{array}$ & $\begin{array}{l}\text { - Main renal artery or vein laceration } \\
\text { or avulsion of hilum } \\
\text { - Devascularized kidney with active } \\
\text { bleeding } \\
\text { - Shattered kidney with loss of } \\
\text { identifiable parenchymal renal } \\
\text { anatomy }\end{array}$ & $\begin{array}{l}\text { - Main renal artery or vein laceration } \\
\text { or avulsion of hilum } \\
\text { - Devascularized kidney } \\
\text { - Shattered kidney with loss of } \\
\text { identifiable parenchymal renal } \\
\text { anatomy }\end{array}$ \\
\hline
\end{tabular}

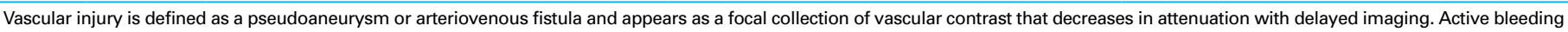
from a vascular injury presents as vascular contrast, focal or diffuse, that increases in size or attenuation in delayed phase. Vascular thrombosis can lead to organ infarction. Grade based on highest grade assessment made on imaging, at operation, or on pathologic specimen. More than one grade of kidney injury may be present and should be classified by the higher grade of injury. Advance one grade for bilateral injuries up to Grade III. AAST: American Association for the Surgery of Trauma; AIS: abbreviated injury scale; CT: computed tomography.

the workup of multiorgan trauma and thus the renal injury is not missed. ${ }^{11}$ All other forms of acute imaging are inferior to $\mathrm{CT}$, including intravenous pyelography (IVP) and ultrasound. A one-shot IVP may be used to determine the presence of a contralateral kidney prior to nephrectomy if the patient has no preoperative imaging. However, $80 \%$ of trauma surgeons either perform no tests or only palpate for the presence of a contralateral kidney prior to opening and exploring the retroperitoneum for an expanding retroperitoneal hematoma. ${ }^{12,13}$

Dual-phase CT scanning is the gold standard for staging renal injuries. Ideally, all CT scans should be supervised by a radiologist to determine whether a urographic phase needs to be performed. Physicians should be aware of their centre's CT scanning protocols in the trauma patient. In our institution, the abdomen is routinely scanned at 70 seconds after the IV bolus (portal venous phase). However, if an abdominal arterial bleeding source (including kidney injury) is suspected, an arterial phase can be added. Not all renal injuries require a delayed pyelogram phase scan. We typically do a delayed scan in Grade 3 and higher injuries or if there is significant fluid around the renal pelvis or hematoma around the kidney.

\section{Treatment}

The vast majority of renal trauma, even high-grade injuries (>Grade 3) may be managed conservatively. ${ }^{13,14}$ This includes bedrest and frequent abdominal examinations, as well as the monitoring of vital signs and degree of hematuria. Frequent monitoring of the hemoglobin during the first 24-48 hours should also be performed. Bedrest is often continued until the hemoglobin is stable and the hematuria has stopped. 


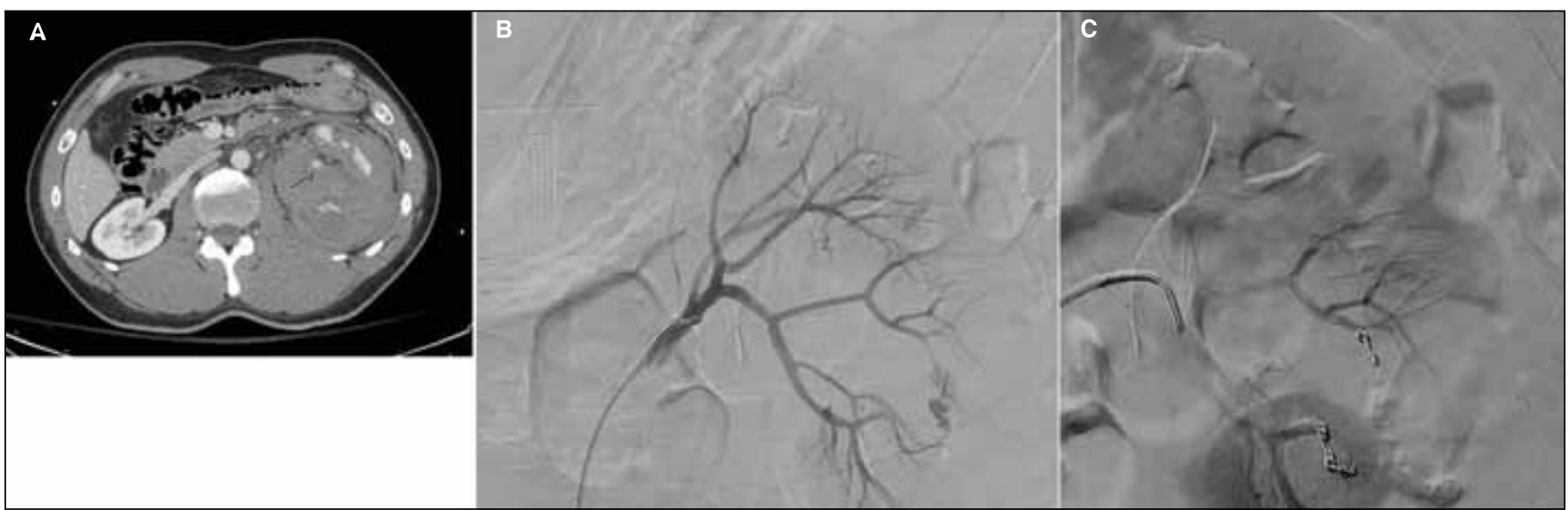

Fig. 1. Grade 4 renal injury with vascular contrast extravasation. Angioembolization of two sites of arterial bleeding. No further urological intervention required.

The need for early (within 24 hours), urgent intervention is based almost solely on the patient's hemodynamic stability.

Another patient factor is concomitant injuries, which may influence timing and choice of intervention. Damagecontrol surgery is a well-established technique to stabilize the severely injured patient. As a urologist, one should be familiar with the surgical techniques that are available and applicable. ${ }^{15,16}$

Also important is resource availability. Patients managed in a community hospital may not have interventional radiology, other surgical subspecialties, or intensive care units readily available.

The final variable affecting outcome is the experience of the surgeon. Patients treated in a non-trauma centre are more likely to undergo nephrectomy compared to those managed in trauma centres. ${ }^{3}$ There are many recently published algorithms and guidelines and, in general, all state the same principles of investigation and management. ${ }^{13,17-19}$ However, these are guidelines only and one must keep in mind the other factors (resource and surgeon) that may dictate the treatment and final outcome.

\section{Treatment by stage}

\section{Grade 1-2 injuries}

These patients can be managed expectantly.

\section{Grade 3 injuries}

These patients can be generally managed expectantly. In the small subset of patients who are actively bleeding, angioembolization should be performed depending on the hemodynamic stability of the patient and availability of interventional radiology. Exploratory renal surgery can be performed with renorraphy; however, depending on surgeon experience, the patient may ultimately have a nephrectomy. ${ }^{1,14}$

\section{Grade 4 injuries (Figs. 1, 2, 3)}

Patients who has VCE on their CT scan can be treated with angioembolization if their clinical status permits. These patients may also be in the angiography suite for control of other sources of bleeding (spleen, pelvis). Patients who are taken immediately to the operating room for bleeding and found to have a rapidly expanding retroperitoneal hematoma will require exploration with either renorrhaphy or nephrectomy. In those severely injured patients who have undergone damage-control packing, angioembolization may be considered if the interventional radiology team can be mobilized in advance. Factors on initial CT that may predict the need for intervention include the size of the peri-renal hematoma $(>3.5 \mathrm{~cm})$, the presence of VCE, a laceration depth $>2.5 \mathrm{~cm}$, and $>3$ lacerations. These patients require close monitoring; however, only $14 \%$ of these high-grade (Grade 3-5) renal injured patients required intervention. ${ }^{13}$

Urinary extravasation can be managed expectantly in the majority of Grade 4 injuries. The question of reimaging is important. Most guidelines suggest reimaging these injuries at 48-72 hours. Limiting the number of CT scans should be considered in young patients to decrease their accumulative radiation dose. Typically, these patients are subjected to multiple CT scans during their trauma workup and management. ${ }^{20-22}$

At our institution, reimaging with CT is not pursued unless a patient's clinical condition changes. Ultrasound is often used to determine whether there is a significant urinoma and this may help determine the need for further CT imaging. This includes signs or symptoms of continued bleeding or sepsis as reported by others. ${ }^{23}$ The rate of ureteral stent intervention or percutaneous drainage for urine leak or infection has been reported to be up to approximately $23 \% .^{14,24,25}$ Patients who have suffered multiorgan abdominal/pelvic injuries are often rescanned for other reasons and it is important that the urologist be part of the trauma/ICU consulting team. The presence of urinary contrast extravasation at 24-48 hours 


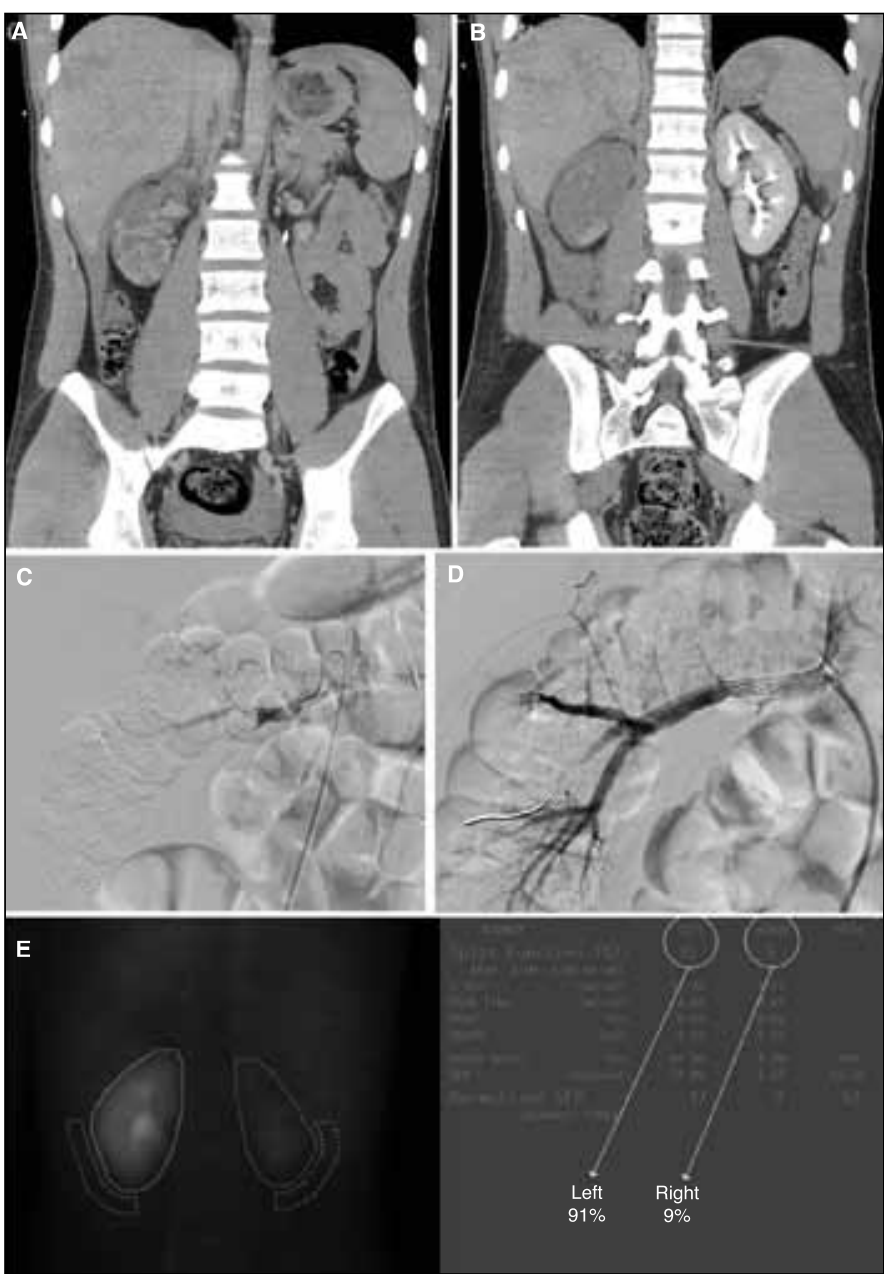

Fig. 2. Grade 4 renal injury with patchy perfusion to kidney. Patient underwent vascular stenting procedure. Followup renal scan performed shows $9 \%$ function to kidney.

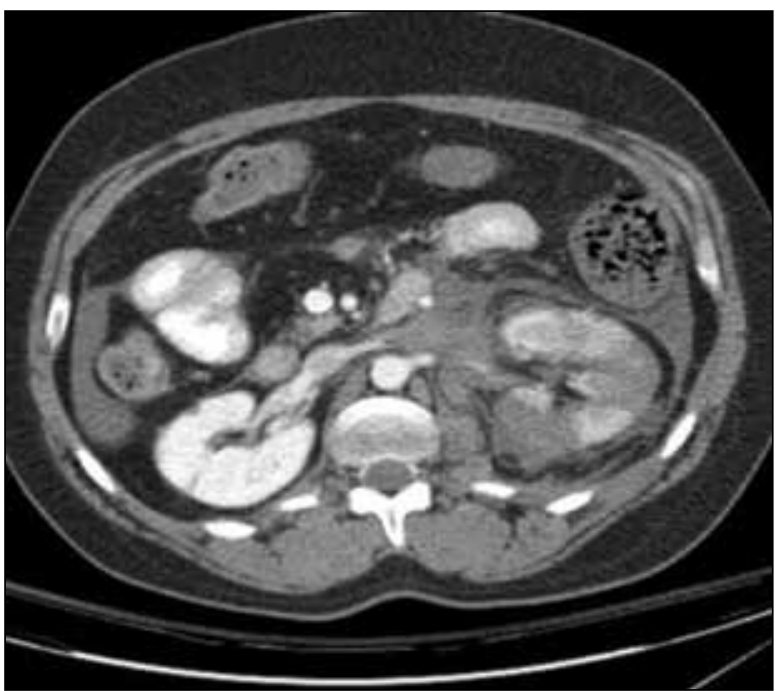

Fig. 4. Grade 5 renal injury: peri-hilar hematoma with left renal vein injury and segmental infarcts from renal artery injury. Managed conservatively.
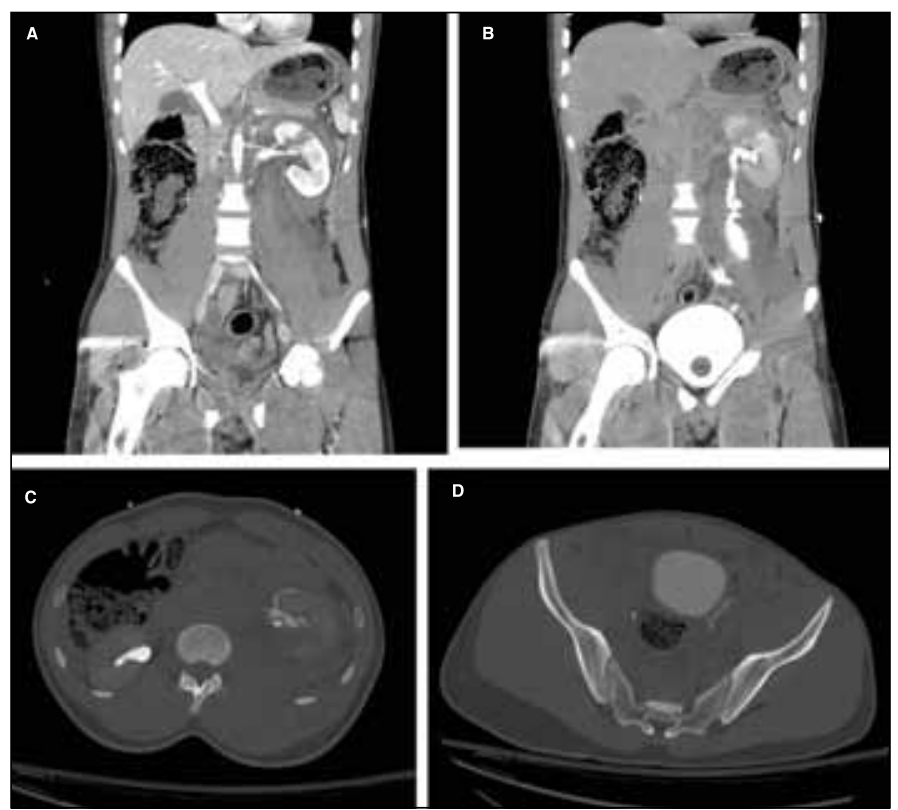

Fig. 3. Patient with Grade 4 renal injury with urinary extravasation. Using computed tomography windows, area of extravasation was from lower pole calyx. Distal ureter can be seen. Treated conservatively, no stent required.

would not be unexpected in some high-grade collecting system injuries. We do not normally intervene in asymptomatic patients on $\mathrm{CT}$ findings alone. There is a theoretical concern that stenting the urinary tract may introduce infection into the hematoma. Also, in those patients with multiple Grade 4 lacerations, it may be difficult to reliably place the coil of the stent in the collecting system rather than in the parenchyma.

Overall, Grade 4 injuries in the stable, non-bleeding patient can be initially managed conservatively. Results have shown that renal salvage is higher compared to exploration; however, those managed conservatively may require minimally invasive intervention. ${ }^{3,14,26}$

\section{Grade 5 injuries (Fig. 4)}

According to the 2018 AAST staging system, these patients have avulsion of the renal hilum or have active bleeding with a devascularized kidney. Although the new staging system defines a shattered kidney as one that has lost identifiable renal anatomy, the author finds this definition unclear. Nevertheless, in the new system, a Grade 5 injury would represent the most serious degree of parenchymal injury. Depending on the patient's clinical situation, he/she can be managed by angioembolization or nephrectomy.

Firearms and stabbings are the most common cause of penetrating injuries in Canada. ${ }^{27}$ In 2013, approximately $1 / 3$ of homicides were caused by firearms and in 2016, this number had increased to approximately $40 \% .{ }^{28}$ As in blunt injuries, if these patients are well-staged, a conservative approach can be taken. ${ }^{5,29,30}$ In those who undergo 
Kodama

laparotomy without preoperative staging, the need for renal exploration again depends on the same factors (bleeding, expanding or pulsatile hematoma). However, zone 2 retroperitoneal hematomas from penetrating trauma are generally explored by trauma surgeons but lateral hematomas may be observed since they are away from the renal hilum. ${ }^{13}$

Long-term complications of renal injuries include hypertension from ischemia (arterial or page), pseudoaneurysms, and arteriovenous fistulas.

\section{Conclusion}

Over the last few decades, there has been a paradigm shift in the management of renal trauma from an operative to a conservative approach. The reason for this is multifactorial. The absolute need for urgent intervention, however, has remained the same: bleeding and hemodynamic instability.

Competing interests: The author reports no competing personal or financial conflicts.

This paper has been peer reviewed.

\section{References}

1. Wessells H, Suh D, Porter JR, et al. Renal injury and operative management in the United States: Results of a population-based study. J Trauma 2003;54:423-30. https://doi.org/10.1097/01. TA.0000051932.28456.F4

2. Bjurlin MA, Fantus RJ, Fantus RJ, et al. The impact of seat belts and airbags on high-grade renal injuries and nephrectomy rate in motor vehicle collisions. J Urol 2014;192:1131-6. https://doi.org/10.1016/i. juro.2014.04.093

3. Hotaling JM, Wang J, Sorensen MD, et al. A national study of trauma level designation and renal trauma outcomes. J Urol 2012;187:536-41. https://doi.org/10.1016/i.juro.2011.09.155

4. Terrier JE, Paparel P, Gadegbeku B, et al. Genitourinary injuries after traffic accidents: Analysis of a registry of 162690 victims. J Trauma Acute Care Surg 2017;82:1087-93. https://doi.org/10.1097/ TA. 0000000000001448

5. Mann U, Zemp L, Rourke KF. Contemporary management of renal trauma in Canada: A 10-year experience at a level 1 trauma centre. Can Urol Assoc J 2018. [Epub ahead of print]. https://doi.org/10.5489/ cuai.5581

6. Moore E, Shackford S, Pachter H, et al. Organ injury scaling: Spleen, liver, and kidney. J Trauma 1989; 29:1664-6. https://doi.org/10.1097/00005373-198912000-00013

7. Buckley J, McAninch JW. Revision of current American Association for the Surgery of Trauma Renal Injury grading system. J Trauma 2011;70:35-7. https://doi.org/10.1097/TA.0b013e318207ad5a

8. Dugi D III, Morey AF, Gupta A, et al. American Association for the Surgery of Trauma Grade 4 renal injury sub-stratification into Grades 4a (low-risk) and 4b (high-risk). J Urol 2010;183:592-7. https://doi.org/10.1016/i.juro.2009.10.015

9. Figler BD, Malaeb BS, Voelzke B, et al. External validation of a sub-stratification of the American Association for the Surgery of Trauma Renal injury scale for Grade 4 injuries. J Am Coll Surg 2013;217:924-8. https://doi.org/10.1016/i.jamcollsurg.2013.07.388
10. Kozar RA, Crandall M, Shanmuganathan $K$, et al; the AAST Patient Assessment Committee. Organ injury scaling 2018 update: Spleen, liver, and kidney. J Trauma Acute Care Surg 2018;85:1119-22. https://doi.org/10.1097/TA.0000000000002058

11. Brandes S, McAninch JW. Urban free falls and patterns of renal injury: A 20-year experience with 396 cases. J Trauma 1999;47:643. https://doi.org/10.1097/00005373-199910000-00007

12. Yeung $L$, Brandes $S$. Contemporary management of renal trauma: Differences between urologists and trauma surgeons. J Trauma 2012;72:68-75. https://doi.org/10.1097/TA.0b013e31823e29f6

13. Brown CV, Alam HB, Brasel K, et al. Western Trauma Association critical decisions in trauma: Management of renal trauma. Trauma Acute Care Surg 2018;85:10210-25. https://doi.org/10.1097/ TA.0000000000001960

14. Keihani S, Xu Y, Presson AP, et al; Genito-Urinary Trauma Study Group. Contemporary management of highgrade renal trauma: Results from the American Association for the Surgery of Trauma Genitourinary Trauma study. J Irauma Acute Care Surg 2018;84:418-25. hitps://doi.org/10.1097/TA.0000000000001796

15. Smith TG III, Coburn M. Damage control maneuvers for urologic trauma. Urol Clin N Am 2013;40:343-50. htrps://doi.org/10.1016/i.ucl.2013.04.003

16. Weber DG, Bendinelli C, Balogh ZJ. Damage control surgery for abdominal emergencies. BJS 2014;101:e109-18. https://doi.org/10.1002/bis.9360

17. Morey AF, Brandes S, Dugi DD, et al. Urotrauma: AUA guideline. J Urol 2014;192:327-35. https://doi. org/10.1016/i.juro.2014.05.004

18. Santucci RA, Wessells $\mathrm{H}$, Bartsch $\mathrm{G}$, et al. Consensus on genitourinary trauma: Evaluation and management of renal injuries: Consensus statement of therenal trauma subcommittee. BJU 2004;93:937-54. https:// doi.org/10.1111/i.1464-4096.2004.04820.x

19. Serafetinides $E$, Kitrey ND, Diakovic N, et al. Review of the current management of upper urinary tract injuries by the EAU trauma guidelines panel. Eur Urol 2015;67:930-6. https://doi.org/10.1016/i. eururo.2014.12.034

20. Kepros JP, Opreanu RC, Samaraweera R, et al. Whole body imaging in the diagnosis of blunt trauma, ionizing radiation hazards, and residual risk. Eur I Trauma Emerg Surg 2013;39:15-24. https://doi.org/10.1007/s00068-012-0201-2

21. Beatty L, Furey E, Daniels C, et al. Radiation exposure from CT scanning in the resuscitative phase of trauma Care: A level one trauma centre experience. CJEM 2015;17:617-23. https://doi.org/10.1017/ cem.2014.61

22. Davies RM, Scrimshire AB, Sweetman L, et al. A decision tool for whole-body CT in major trauma that safely reduces unnecessary scanning and associated radiation risks: An initial exploratory analysis. Injury 2016;47:43-9. https://doi.org/10.1016/i.injury.2015.08.036

23. Long JA, Fiard G, Descotes JL, et al. High-grade renal injury: Non-operative management of urinary extravasation and prediction of long-term outcomes. BJU Int 2103;111:E249-55.

24. Davis $P$, Bultitude MF, Koukounaras J, et al. Assessing the usefulness of delayed imaging in routine followup for renal trauma. J Urol 2010;184:973-7. https://doi.org/10.1016/i.juro.2010.04.070

25. Bayne DB, Tresh A, Baradaran N, et al. Does routine repeat imaging change management in high-grade renal trauma? Results from three level 1 trauma centres. World I Urol 2018. [Epub ahead of print]

26. Bjurlin MA, Fantus RJ, Fantus RJ, et al. Comparison of non-operative and surgical management of renal trauma: Can we predict when non-operative management fails? J Trauma Acute Care Surg 2017;82: 356-61. https://doi.org/10.1097/TA.0000000000001316

27. Juristat Bulletin-Quick Fact Firearm-related violent crime in Canada

28. Police-reported crime statistics, 2017 Released at 8:30 a.m. Eastern time in The Daily, Monday, July 23, 2018 Statistics Canada

29. Hadjpavlou M, Grouse E, Gray R, et al. Managing penetrating renal trauma: Experience from two major trauma centres in the UK. BJU Int 2018;121:928-34. https://doi.org/10.1111/bju. 14165

30. Keihani S, Putbrese BE, Rogers DM, et al; in conjunction with the Trauma and Urologic Reconstruction Network of Surgeons. The associations between initial radiographic findings and interventions for renal hemorrhage after high-grade renal trauma: Results from the Multi-institutional Genito-Urinary Trauma Study (MiGUTS). J Trauma 2019. [Epub ahead of print]

Correspondence: Dr. Ron Kodama, Division of Urology, Department of Surgery, University of Toronto, Toronto, ON, Canada; ron.kodama@sunnybrook.ca 